\title{
The public perception of the anaesthesiologist in Romania:
}

\section{a survey}

\author{
Adela Hilda Onutu ${ }^{1}$, Cristina Rus ${ }^{2}$, Iurie Acalovschi ${ }^{3}$ \\ ${ }^{1}$ Emergency Clinic County Hospital, Cluj-Napoca, Romania \\ 2 "Octavian Fodor" Institute of Gastroenterology and Hepatology, Cluj-Napoca, Romania \\ 3 "Iuliu Hatieganu” University of Medicine and Pharmacy, Cluj-Napoca, Romania
}

\begin{abstract}
Background. Previous studies have shown that the public perception of anaesthesiologists' duties regarding perioperative management lacks a good understanding. The aim of this study was to assess the public perception of the anaesthesiologist's role before, during and after surgery, in Romania.

Method. The prospective cross-sectional study was undertaken between January 2015 and August 2016. A questionnaire that comprised 23 questions was uploaded on Google at https://docs.google.com/ forms/d/1KxC8jSYydhEu3pn0HrOLHEsuCEQLSEHQqUo_HzrHuw8/viewform. The link was forwarded on-line randomly (mail, social media). The questions were structured based on current literature. Inclusion criteria were people aged $>15$ years and not directly related to any medical activity. The answers were anonymously registered, in real time, in an Excel format, used later to process the statistics.

Results. 1153 people completed the questionnaire, $61 \%$ female and $39 \%$ male, $80.8 \%$ being from the urban area and $19.2 \%$ from the countryside. $62.7 \%$ were hospitalized in the past, and $49.8 \%$ had undergone at least one surgery. From the questioned group $65.2 \%$ had graduated university, and $64.3 \%$ were aged between 20 and 40 years. A majority of 1089 respondents (94.6\%) knew that the anaesthesiologist was responsible for providing anaesthesia in the operating room. $26.6 \%$ considered that the surgeon and the anaesthesiologist played different roles in OR, but $54.4 \%$ understood that there is a collaboration between them during surgery. Only $36.2 \%$ were aware that the anaesthesiologist replaces blood losses and provides patients hemodynamic stability and proper oxygenation during surgery. $54.6 \%$ believe that the surgeon decides upon the postoperative pain management and only $32 \%$ know the anaesthesiologist is the physician in charge of intensive care patients. $79.5 \%$ of respondents are willing to receive from their anaesthesiologist detailed information, regarding anaesthesia and postoperative care, before surgery, and consider that more publicity should be made regarding this profession.

Conclusion. The public perception of the anaesthesiologist's role in Romania is inaccurate in spite of the fact that a large group in our study comprised highly educated people living in urban areas. We consider that further strengthening of the anaesthesiologist/patient relationship and an increased media exposure of our specialty would help to improve its social perception.
\end{abstract}

Keywords: anaesthesiologist, public perception, responsibilities, survey

\section{Introduction}

Anaesthesiology and Intensive Care developed as a necessity, as a service profession for surgery, but it received large scale dimensions outside the operating

Address for correspondence:

Dr. Adela Hilda Onutu

Orthopaedic and Traumatology Clinic Emergency Clinic County Hospital 47-49, General Traian Mosoiu Street Cluj-Napoca, Romania

E-mail: adela_hilda@yahoo.com room, along with the evolution of Intensive Care Units (ICU) and the need for acute and chronic pain therapy.

Romania's entry into the European Union brought along the fundamental freedom of travel and the possibility for Romanian specialists to freely practice their activity in other countries. This event led to the migration of many anaesthesiologists towards economically more developed countries [1].

Apart from the low income, the need for social recognition may have represented another reason which led to the high migration rate of anaesthesiologists, in the past years. Some studies have raised attention to 
the general public reflection of our specialty and showed similar results [2-8].

This study aimed to explore the level of public knowledge concerning the Romanian anaesthesiologist and its responsibilities, and also some modalities to raise the public's attention on our everyday work.

\section{Methods}

Between January 2015 and August 2016 we undertook a prospective, cross-sectional survey-type study. The main inclusion criteria were: Romanian citizens not directly related to any medical activity and aged above 15 years.

A questionnaire was created based on the current literature data and included 23 questions (Appendix), posted on the Google Survey platform. The link to the form is https://docs.google.com/forms/d/ $1 \mathrm{KxC} 8 \mathrm{jSY}$ ydhEu3pn0Hr0LHEsuCEQLSEHQqUo_HzrHuw8/ edit. The link was randomly distributed across the country, by e-mail, posted on social media and apart from these, questionnaires were printed to be filled in face to face, this direct mode of interrogation being addressed mainly to people, from the rural areas.

Questions were grouped into eight categories and requested information about demographic data (sex, age, urban/rural area, education level, previous surgery, and previous hospitalization) and the responder's opinion about the role of anaesthesiologist before and during surgery, related to prescribing medication, sustaining vital functions and resuscitation. The form also included questions regarding postoperative pain management, the role of anaesthesiologists in the emergency department, in critical situations on the ward, the operating theater and in the ICU. Finally, the last group of items was related to the modalities of providing future information about anaesthesia and surgery. The recording of the education level was done using three degrees: low (gymnasium), medium (high school) and high (university/academic).

The questionnaires were anonymously filled in, and the on-line data was registered in the Google Survey database, in real time, in Excel-type tables. The handfilled self-administered printed forms were later fed into this database.

According to the National Statistics Institute [9], and our sample size calculation, 1100 responses are considered representative of Romania's population (around 19 million) with an accepted error of 3\% and a confidence interval of $95 \%$. Data are expressed as numbers and percentages.

\section{Results}

1153 people answered the questionnaire, $61 \%$ females and $39 \%$ males. The population age distri- bution is shown in Table 1. The superior education level was most prevalent $(65.2 \%)$. The regional allocation of the respondents was $80.8 \%$ from urban areas and $19.2 \%$ from the countryside. Concerning the medical history, $49.8 \%$ of the respondents had undergone surgery, and $62.7 \%$ were hospitalized. The distribution of the respondents over the Romanian counties is shown in Figure 1.

Table 1. Demographic data

\begin{tabular}{ll}
\hline Age & $\%$ \\
$15-20$ & 5.6 \\
$20-30$ & 30.6 \\
$30-40$ & 33.7 \\
$40-50$ & 17.3 \\
over 60 & 12.8 \\
Sex & \\
female & 61 \\
male & 39 \\
Education & \\
primary & 8 \\
medium & 26.8 \\
high & 65.2 \\
Urban/Rural Area & \\
urban & 80.8 \\
rural & 19.2 \\
\hline
\end{tabular}

When questioned about who is performing anaesthesia in the operating room 1089 (94.6\%) answered that the anaesthesiologist is the one responsible. Regarding the relationship between the surgeon and the anaesthesiologist during surgery, $26.6 \%$ of the respondents considered that each plays an independent role, but only $54.4 \%$ understood that there is a collaboration between them, during surgery. We found out that $39.7 \%$ of the respondents considered that the surgeon is the one who decides whether the patient has to be operated on or not, $9.8 \%$ the anaesthesiologist and $46.7 \%$ that the surgeon and anaesthesiologist agree together, while $3.4 \%$ were unable to answer. Concerning the preoperative fasting period and the medication to be administrated before surgery, $58.5 \%$ believed that this is the anaesthesiologist's responsibility, $32.3 \%$ the surgeon's, $1.7 \%$ the nurse's and $7.6 \%$ did not know the answer.

Regarding the intraoperative responsibilities, $91.1 \%$ of the respondents considered that the anaesthesiologist is the one who performs anaesthesia and monitors and stabilizes vital signs during surgery, but fewer people knew about the other intraoperative duties of the anaesthesiologist (Figure 2). But when asked who is responsible for the patient's hemodynamic stability and proper oxygenation during surgery, $22 \%$ answered that 


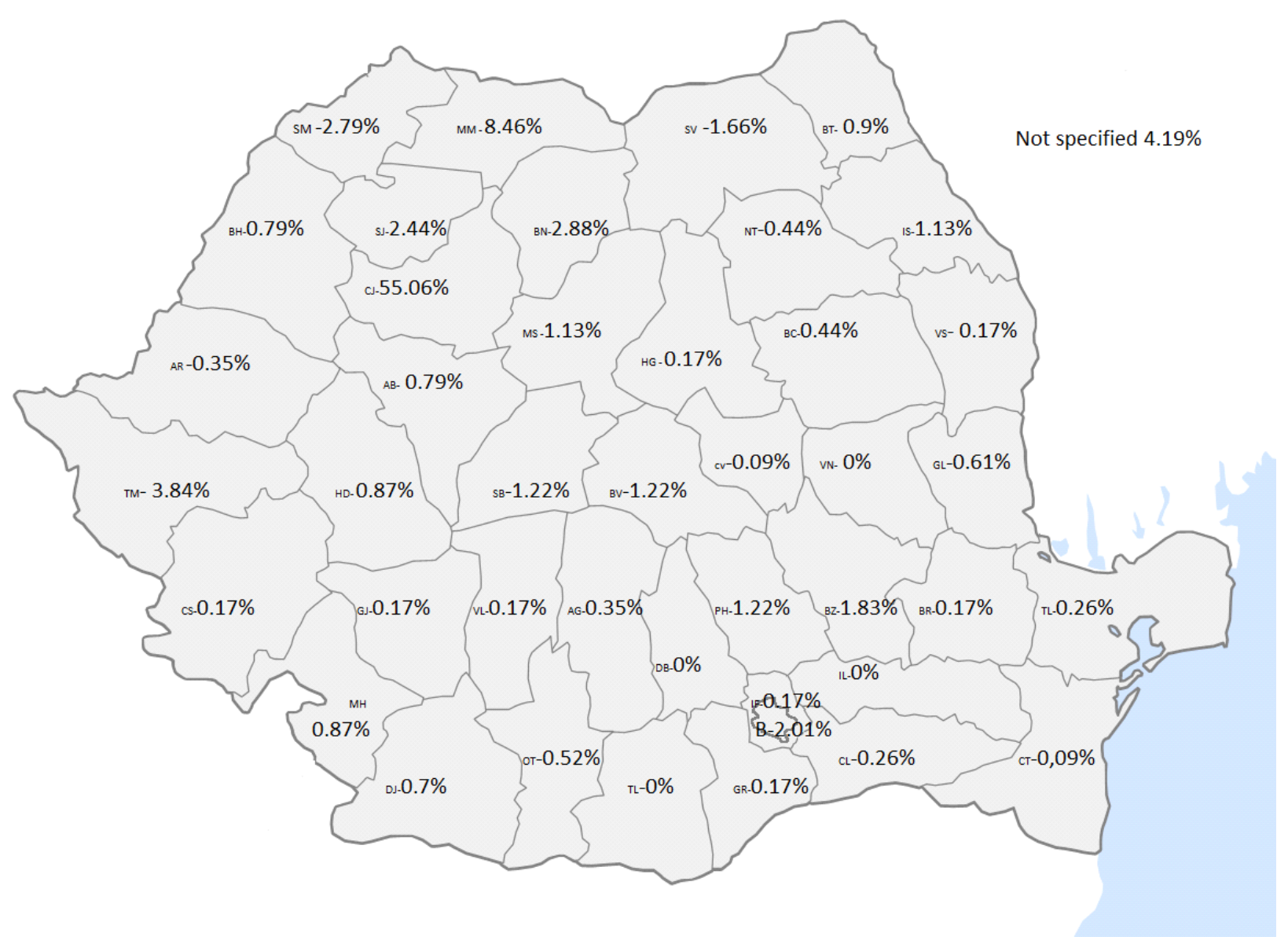

Fig. 1. The territorial distribution of the respondents

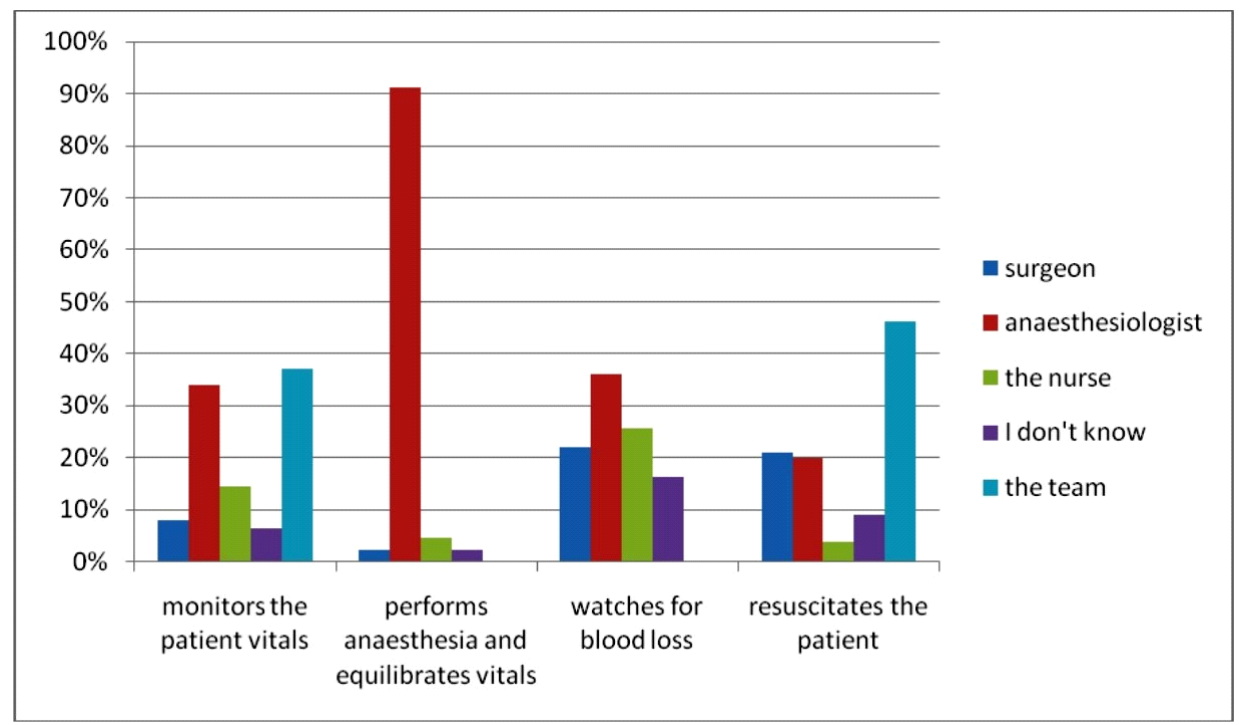

Fig. 2. Respondents' opinions regarding the responsibilities of the anaesthesiologist during surgery

the surgeon does, $36.2 \%$ the anaesthesiologist, $25.6 \%$ the nurse, and $16.2 \%$ did not know the answer. We found that $31.7 \%$ of the respondents believed that the anaesthesiologist ensures patient's safety in the recovery room, another $34.2 \%$ thought that the nurse and $28.3 \%$ the anaesthesia team, while $5.8 \%$ suggested the surgeon was in charge with this activity.

$41.4 \%$ of the responders believed that only the surgeon is responsible for the first 24 postoperative hours, while $26.6 \%$ thought it was the anaesthesiologist, 
$25.9 \%$ the nurse and $6.2 \%$ were unable to answer. Concerning the postoperative acute pain therapy, $54.6 \%$ believed that the surgeon is the one who prescribes it, $29.9 \%$ the anaesthesiologist, $9.1 \%$ the nurse and $6.3 \%$ did not know the answer (Figure 3).

When asked about the anaesthesiologist's duties outside the OR, only $32 \%$ knew that he/she is responsible for the patients in the ICU, 26.3\% that he manages emergency situations on the ward and $24.2 \%$ knew about acute and chronic pain therapy activities (Table 2).

Table 2. Respondents' opinions regarding anaesthesiologist activity in the hospital

\begin{tabular}{|ll|}
\hline Activity & $\begin{array}{l}\text { Number of positive } \\
\text { answers }\end{array}$ \\
\hline Providing anaesthesia in OR & $1108(96.4 \%)$ \\
\hline Providing treatment in ER & $190(16.5 \%)$ \\
\hline Taking care of patients in ICUs & $368(32 \%)$ \\
$\begin{array}{l}\text { Providing regional anaesthesia in OR } \\
\text { Cardio-respiratory resuscitation on } \\
\text { the ward }\end{array}$ & $302(26.3 \%)$ \\
\hline Acute and chronic pain therapy & $278(24.2 \%)$ \\
\hline
\end{tabular}

OR - operating room; ER - emergency room; ICU - intensive care unit

Regarding those responders with a surgical history, $41.9 \%$ obtained information on anaesthesia and surgery, before they underwent the procedure and $58.1 \%$ did not.

A high majority of respondents $-79.5 \%$ would like detailed information about anaesthesia, before surgery, from a physician specialized in anaesthesia, while
$13.6 \%$ would like only general information, $4.2 \%$ would not like information at all, and $2.7 \%$ could not decide.

$86.1 \%$ of the respondents consider education and an active attitude of the anaesthesiologist mandatory, as a contribution to the public's medical education; $6.4 \%$ do not consider it, and $7.5 \%$ did not answer.

About the statement that "a good medical education of the population can help reduce the healthcare costs": $81.4 \%$ agreed, $8 \%$ did not and $10.5 \%$ did not know.

Regarding the modalities on acquiring information, $66.8 \%$ targeted internet providers, $60 \%$ TV shows or advertising and $58.1 \%$ indicated school.

\section{Discussion}

This first study that investigated people's perception of the anaesthesiologist's activity and responsibilities in Romania was addressed randomly. It differs from other studies in which the respondents were patients planned for elective surgery [3, 6, 10-17]. We tried to obtain a more objective perspective of people's perception looking to a whole heterogeneous sample of the population, as this would give a better image of our reflection. Further, this might offer a tool in approaching people who attend the surgery for the first time, helping them to receive the correct and complete set of information.

We found that $92.9 \%$ of the respondents knew that the anaesthesiologist provides anaesthesia as opposed to other studies where the percentage varied between $25.2 \%$ and $86 \%[3,11-16]$. This rather higher rate could be explained by a significant number of respondents with high degrees of education (65.2\%), but also by a reduced concern of social desirability bias because

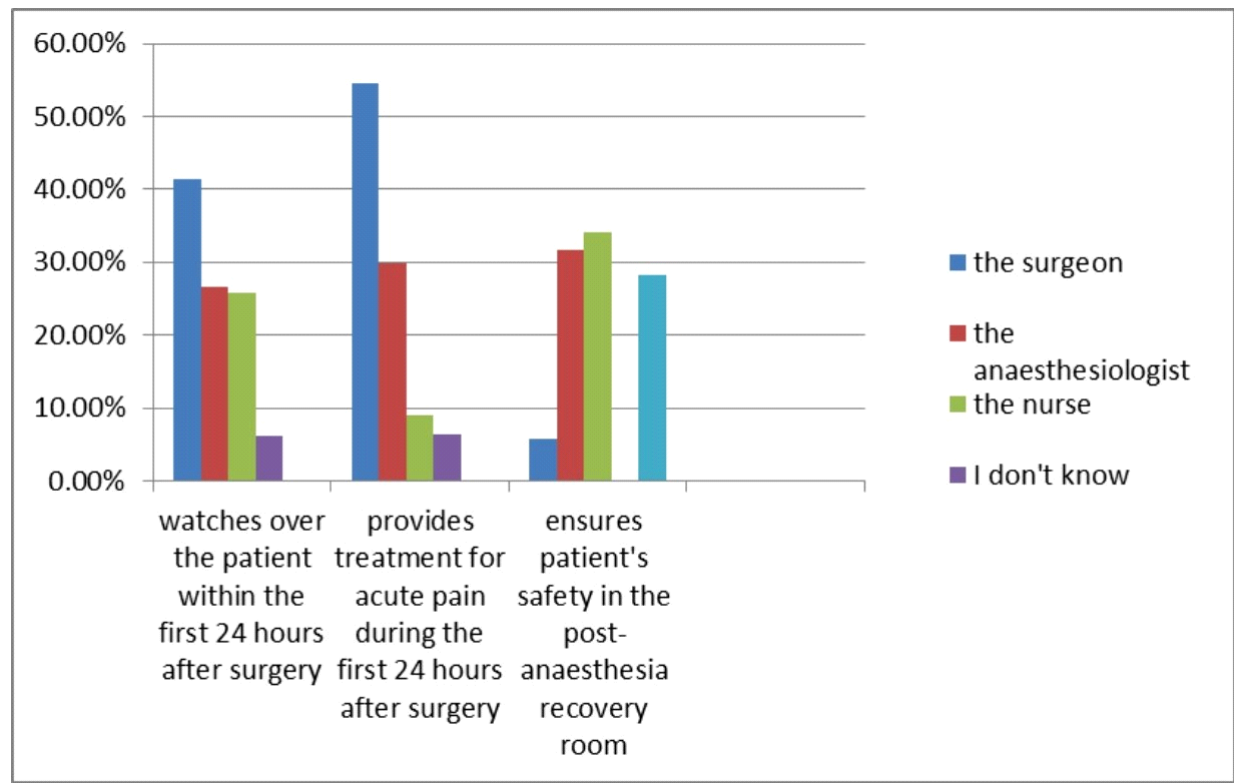

Fig. 3. Respondent's opinions about some responsibilities on the day of surgery 
some respondents were aware that an anaesthesiologist distributed the polls.

About the role of the anaesthesiologist in the preoperative period, $39.7 \%$ of the interviewees believe that the one who decides upon the operability of a patient is the surgeon, while $46.7 \%$ think that this decision is made together by both the surgeon and the anaesthesiologist. Another study showed that $86.5 \%$ of the respondents believe that the decision belongs exclusively with the surgeon [16]. Concerning the decision regarding fasting time, $58.5 \%$ of the respondents in our study think that it is the anaesthesiologist's responsibility, compared to $70.8 \%$ in a previous study [16]. Garcia-Marcinkiewicz et al. (11) found that only $13 \%$ consider that the anaesthesiologist is responsible for transfusions, a much lower figure than $36.2 \%$, as we found in our study. Concerning intraoperative resuscitation, in our study, $46.2 \%$ believe that this is done by the team of the anaesthesiologist and surgeon, while Acosta-Martínez et al. [13] found that $37.6 \%$ of his respondents considered that the surgeon is the one who does the resuscitation, when necessary.

For the postoperative period, Swinhoe et al. [3] reported that safety in the post-anaesthesia room is the responsibility of the anaesthesia team in $55 \%$ of respondents, compared to $28.3 \%$ that we found in our study.

An important finding is that $79.5 \%$ of the interviewees would wish to get detailed information about anaesthesia before surgery. Thus efforts should be made for improving the communication between the anaesthesiologists and the surgical patients. Improving communication represent a major way of improving our reflection in people's perception. Many anaesthesiologists avoid doing this because of time pressure and because they believe that too many details offered to the patient might raise his/her anxiety level before surgery and thus increase all unwanted side-effects. We found that $20.5 \%$ of the respondents do not wish detailed information before surgery and we consider this percent high and difficult to explain. There could be many entirely different reasons for this behaviour: extreme fear, a great trust in the medical staff or strong religious belief. These results are similar to those found by Lee et al. (16) as $26.4 \%$ responders in their study did not expect detailed information before surgery, because of anxiety.

Although our study shows a high degree of knowledge about our activity in OR, it seems that Romanian population still lacks accurate information about the anaesthesiologist's responsibilities outside OR. These responsibilities include taking care of patients in ICU, in the emergency department, as well as providing anaesthesia/analgesia outside OR and providing pain therapy (Table 2).
Our data showed that about $6 \%$ of the respondents did not know how to respond to several questions. Even if $49.8 \%$ of the interviewees have experienced at least one surgery, before; they could not answer correctly all the questions, probably meaning that they had not received enough information at the time of their surgery.

The results of this study highlighted the need for providing more information to the public, a goal which could be reached by developing a project at a national level, which would improve the multimedia reflection of our specialty and would help improve the general public perception.

We have found differences with other studies, and these are basically due to the cultural background and probably to the difficulties in implementing complete and robust preoperative information of the patients and their families, in our country. Opposite to other studies [11-17] where the questionnaire was administered directly, in this study the form was shared randomly, and it was filled anonymously, by people who had or not previously had contact with the surgical, medical staff.

The majority of the responses came from the northwestern part of the country, and also the majority of the respondents had a high level of education, and this could show a lack of uniformity of the investigated sample.

Future studies with a homogenous distribution would monitor more objectively the evolution of the public's reflection on the Romanian anaesthesiologists' activities.

In conclusion, the data obtained showed an incomplete perception concerning the anaesthesiologist and in addition that his responsibilities are still insufficiently understood. An improved anaesthesiologist/patient relation should be developed, and more efforts should be made to inform the public correctly about anaesthesiologist activities and responsibilities.

\section{Conflict of interest}

Nothing to declare

\section{References}

1. Mitre C, Breazu C, Mitre I, Filipescu D. Migration of skilled anaesthesologists from low to high-income economies: Urgent action needed. Eur J Anaesthesiol 2016; 33: 157-159. DOI: 10.1097/EJA.0000000000000382

2. vanWijk MG, Smalhout B. A postoperative analysis of the patient's view of anaesthesia in a Netherlands' teaching hospital. Anaesthesia 1990; 45: 679-682. DOI: 10.1111/j.13652044.1990.tb14399.x

3. Swinhoe CF, Groves ER. Patients' knowledge of anaesthetic practice and the rôle of anaesthesiologists. Anaesthesia 1994; 49: 165-166. DOI: 10.1111/j.1365-2044.1994.tb03380.x 
4. Chew ST, Tan T, Tan SS, Ip-Yam PC. A survey of patients' knowledge of anaesthesia and perioperative care. Singapore Med J 1998; 39: 399-402

5. Huang Y, Yang K, Ren H, Luo A. A survey of elective surgical patients' attitudes toward anesthesia in PUMC hospital. Chin Med Sci J 2002; 17: 77-80

6. Calman LM, Mihalache A, Evron S, Ezri T. Current understanding of the patient's attitude toward the anesthetist's role and practice in Israel: effect of the patient's experience. J Clin Anesth 2003; 15: 451-454. DOI: 10.1016/S09528180(03)00111-9

7. Tohmo H, Pälve H, Illman H. The work, duties and prestige of Finnish anesthesiologists: patients' view. Acta Anaesthesiol Scand 2003; 47: 664-666. DOI: 10.1034/j.1399-6576.2003.00152.x

8. Braun AR, Leslie K, Morgan C, Bugler S. Patients' knowledge of the qualifications and roles of anaesthetists. Anaesth Intensive Care 2007; 35: 570-574

9. Institutul Național de Statistică [Online]. [2016?] [cited 2016 December 09]. Available from: URL: http://www.insse.ro/cms/

10. Saal D, Heidegger T, Nuebling M, Germann R. Does a postoperative visit increase patient satisfaction with anaesthesia care? Br J Anaesth 2011; 107: 703-709. DOI: 10.1093/bja/aer261

11. Garcia-Marcinkiewicz AG, Long TR, Danielson DR, Rose SH. Health literacy and anesthesia: patients' knowledge of anaesthesiologist roles and information desired in the preope- rative visit. J Clin Anesth 2014; 26: 375-382. DOI: 10.1016/ j.jclinane.2014.01.013

12. Irwin MG, Fung SK, Tivey S. Patients' knowledge of and attitudes towards anaesthesia and anaesthetists in Hong Kong. Hong Kong Med J 1998; 4: 16-22

13. Acosta-Martínez J, Guerrero-Dominguez R, López-HerreraRodríguez D, Sánchez-Carrillo F. Rol del anestesiólogo: punto de vista de los pacientes [The anaesthetist's role from the patient's perspective]. Rev Colomb Anestesiol 2016; 44: 121 127. DOI: $10.1016 /$ j.rca.2016.02.010

14. Sobrinho Ribeiro C, de Barros Mourão JI. Anaesthesiologist: the patient's perception. Rev Bras Anestesiol 2015; 65: 497-503. DOI: 10.1016/j.bjane.2014.05.014

15. Aydin Erden I, Tütüncü R. Patients' knowledge and attitudes about the role of anesthesiologists in a military hospital. J Clin Exp Invest 2012; 3: 313-317. DOI: 10.5799/ ahinjs.01.2012.03.0170

16. Lee JJ, Lee NH, Park CM, Hong SJ, Kong MH, Lee KH, et al. Public awareness about the specialty of anesthesiology and the role of anesthesiologists: a national survey. Korean J Anesthesiol 2014; 66: 12-17. DOI: 10.4097/kjae.2014.66.1.12

17. Hariharan S, Merritt-Charles L, Chen D. Patient perception of the role of anesthesiologists: a perspective from the Caribbean. J Clin Anesth 2006; 18: 504-509. DOI: 10.1016/ j.jclinane. 2006.03 .004

\section{Appendix - The 23 questions of the online-published survey}

A.

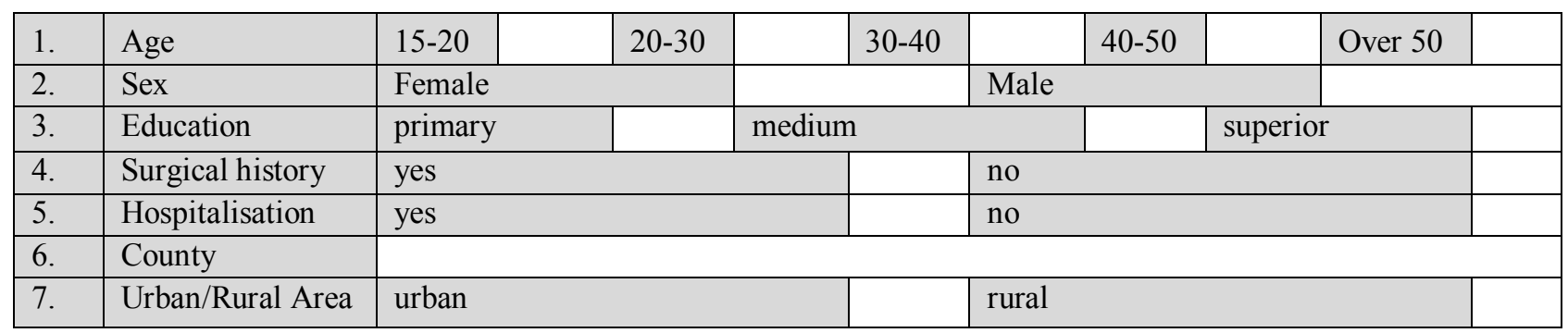

B.

1. Who is responsible for performing anaesthesia in the operating room?

\begin{tabular}{|c|c|c|c|c|}
\hline the surgeon & the technician & the anaesthesiologist & the nurse & I don't know \\
\hline \multicolumn{5}{|c|}{ 2. What is the relationship between surgeon and anaesthesiologist during surgery? } \\
\hline $\begin{array}{l}\text { the team is led by } \\
\text { surgeon }\end{array}$ & $\begin{array}{l}\text { the team is led by } \\
\text { anaesthsiologist }\end{array}$ & $\begin{array}{l}\text { each plays diferent } \\
\text { parts }\end{array}$ & $\begin{array}{l}\text { They collaborate } \\
\text { during surgery }\end{array}$ & I don’t know \\
\hline
\end{tabular}

C.

1. Who is responsible for performing anaesthesia in the operating room?

\begin{tabular}{|l|l|l|l|l|l|l|}
\hline the surgeon & the technician & the anaesthesiologist & the nurse & I don't know & \\
\hline 2. What is the relationship between surgeon and anaesthesiologist during surgery? & I don't know \\
\hline $\begin{array}{l}\text { the team is led by } \\
\text { surgeon }\end{array}$ & $\begin{array}{l}\text { the team is led by } \\
\text { anaesthsiologist }\end{array}$ & $\begin{array}{l}\text { each plays diferent } \\
\text { parts }\end{array}$ & $\begin{array}{l}\text { They collaborate } \\
\text { during surgery }\end{array}$ & \\
\hline
\end{tabular}


D.

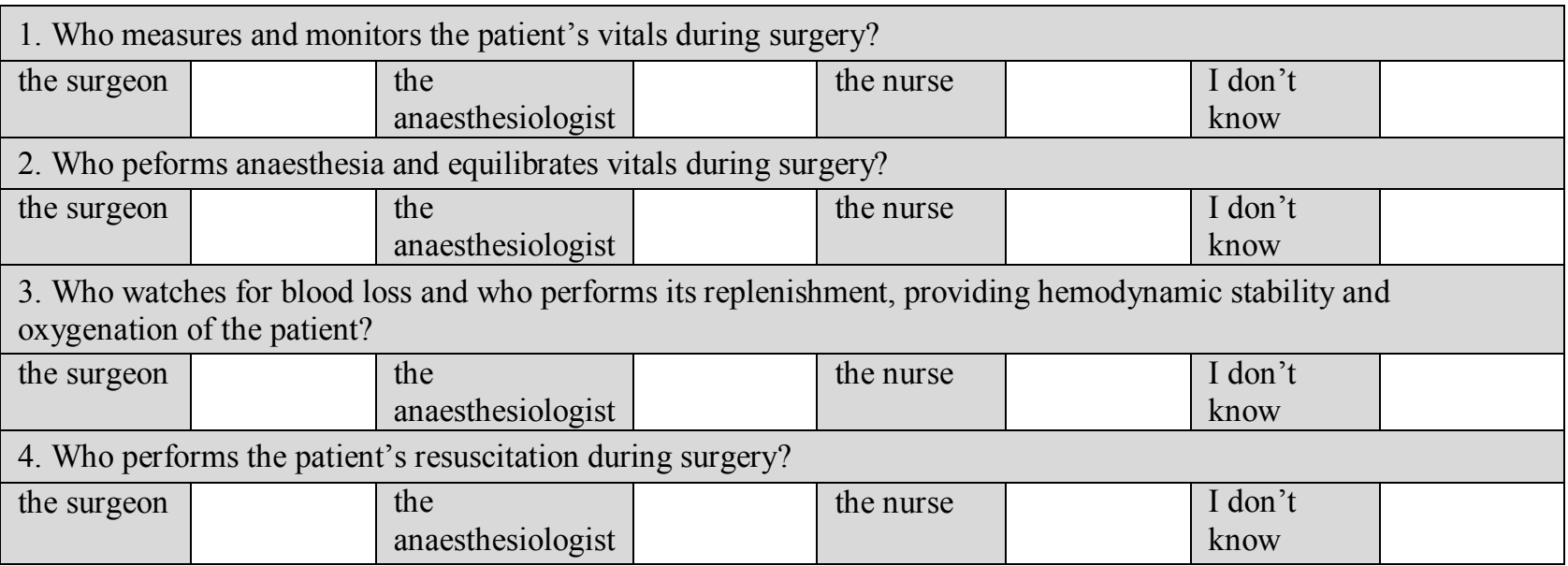

E.

1. Who is the one who watches over the patient within the first 24 hours after surgery?

\begin{tabular}{l|l|l|l|l|l|l|}
\hline the surgeon & $\begin{array}{l}\text { the } \\
\text { anaesthesiologist }\end{array}$ & the nurse & \multicolumn{1}{l}{$\begin{array}{l}\text { I don't } \\
\text { know }\end{array}$} & \\
2. Who provides treatment for acute pain postoperatively (24 hours)? & the nurse & $\begin{array}{l}\text { I don't } \\
\text { know }\end{array}$ & \\
\hline the surgeon & $\begin{array}{l}\text { the } \\
\text { anaesthesiologist }\end{array}$ & & & $\begin{array}{l}\text { I don't } \\
\text { know }\end{array}$ & \\
3. Who ensures patient's safety in the post-anesthesia recovery room? & the nurse & & $\begin{array}{l}\text { the } \\
\text { anaesthesiologist }\end{array}$ \\
the surgeon
\end{tabular}

F.

\begin{tabular}{|l|l|}
\hline \multicolumn{2}{|l|}{ What is the anaesthesiologist's role in a hospital (multiple answers)? } \\
\hline performing anaesthesia in the operating room & \\
\hline emergency treatment for emergencies & \\
\hline caring for the patient in ICU & \\
\hline performing local anaesthesia în OR & \\
\hline resuscitation of patients anywhere in the hospital & \\
\hline pain therapy in pain clinic & \\
\hline
\end{tabular}

G.

\begin{tabular}{|l|l|}
\hline \multicolumn{2}{|l|}{ Would you like information about anaesthesia, before surgery, from a doctor specialized in anaesthesia? } \\
\hline yes, I would like detailed information & \\
\hline yes, I would like information, but not detailed & \\
\hline no & \\
\hline I don't know & \\
\hline
\end{tabular}


H.

\begin{tabular}{|c|c|c|c|c|}
\hline \multicolumn{5}{|c|}{ 1. Have you so far obtained information on anaesthesia and $s$} \\
\hline \multicolumn{2}{|c|}{ If YES: where did you obtain this information? } & \multicolumn{3}{|c|}{$\begin{array}{l}\text { If NO: what means do you think useful for updating the } \\
\text { public's consciousness on the role and activity of the } \\
\text { anaesthesiologist. }\end{array}$} \\
\hline \multicolumn{2}{|l|}{-the internet } & $-\mathrm{TV}$ & & \\
\hline \multicolumn{2}{|l|}{-TV } & -newspapers & & \\
\hline \multicolumn{2}{|l|}{-radio } & -the internet & & \\
\hline \multicolumn{2}{|l|}{$\begin{array}{l}\text {-magazines / newspapers / } \\
\text { other brochures }\end{array}$} & -radio & & \\
\hline \multirow[t]{2}{*}{-other } & & -school & & \\
\hline & & -other & & \\
\hline \multicolumn{5}{|c|}{$\begin{array}{l}\text { 2. Do you consider the education and active attitude of the anaesthesiologist to be necessary in contributing to the } \\
\text { public's medical education? }\end{array}$} \\
\hline yes & no & & I don't know & \\
\hline \multicolumn{5}{|c|}{ 3. Do you consider that a good medical education of the population can help reduce healthcare costs? } \\
\hline yes & no & & I don't know & \\
\hline
\end{tabular}

